\title{
Use of recreational drugs for sex in recent HIV seroconverters
}

Oskar Ayerdi, Mar Vera, Teresa Puerta, Juan Ballesteros Petunia Clavo, Jorge Pérez, Mónica García, Montserrat Raposo, Carmen Rodríguez y Jorge Del Romero. Centro Sanitario Sandoval, IdISSC, Madrid

\section{Background}

To evaluate the influence of recreative drugs consumption in risky sexual practices for acquiring HIV and other sexually transmitted infections (STIs).

\section{Methods}

Descriptive study of patients with a recent seroconversion to HIV infection documented in less than 12 months during 2014-2016 in an STI clinic in Madrid. A structured questionnaire was enrolled to assess risk behaviors, and all patients were screened for other STI.

\section{Results \\ From 2014 until $2016 \rightarrow 857$ New HIV diagnoses $100 \%$ Sexually Transmission}

Recent Seroconvertor (rSCV): Person diagnosed to HIV with documented negative serology in the previous $12 \mathrm{months}$ ( $\pm 6 \mathrm{~m}$ ).

\section{$18.9 \%$ rSCV $(n=162)$}

\section{Gender}

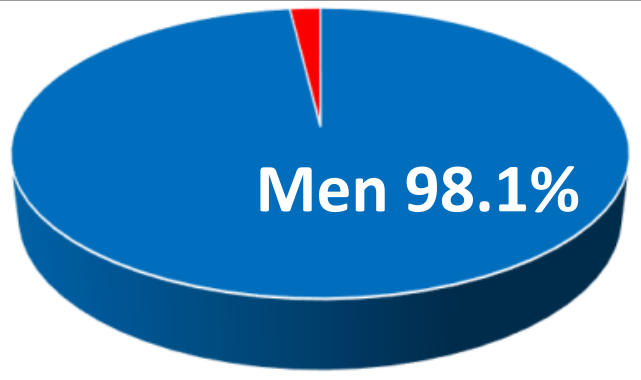

Sexual Orientation

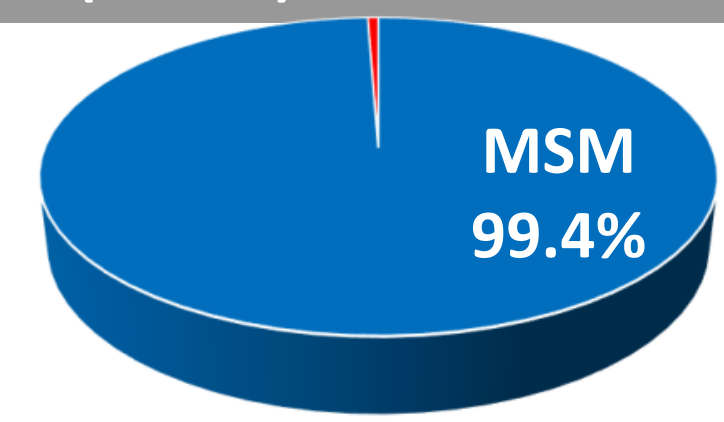

The $6.3 \%$ of MSM and one of the three women were sex workers

\begin{tabular}{|c|c|c|}
\hline $\begin{array}{c}\text { Influence of recreational drugs use in } \\
\text { sexual practices }\end{array}$ & $\begin{array}{c}\text { UPS under the effect of recreational drugs } \\
(\mathbf{n}=119)\end{array}$ & $\begin{array}{c}\text { NO UPS under the effect of recreational } \\
\text { drugs }(\mathbf{n}=\mathbf{4 3})\end{array}$ \\
\hline$>10$ sex partners/last year & $69.7 \%$ & $44.2 \%$ \\
\hline 100 sex partners/life & $67.2 \%$ & $60.5 \%$ \\
\hline STI History & $81.5 \%$ & $60.5 \%$ \\
\hline Concomitant STI & $54.6 \%$ & $41.9 \%$ \\
\hline
\end{tabular}

UPS: Unprotected sex

The $75.9 \%$ (n=123) of the rSCV 2014-2016 had a History of STI

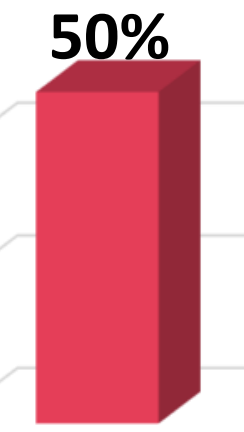

Gonorrhea

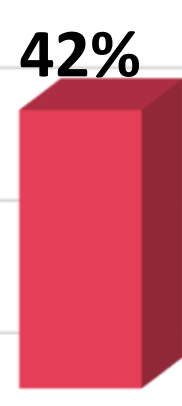

Syphilis

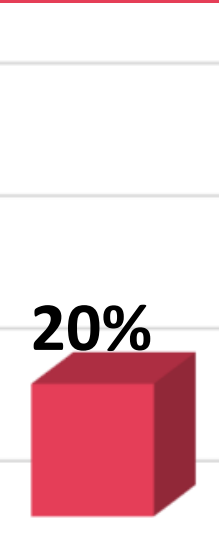

Chlamydia

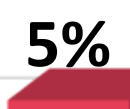

LGV
The $51.2 \%(n=83)$ of the rSCV had a Concomitant STI to the diagnosis of HIV. 2014-2016

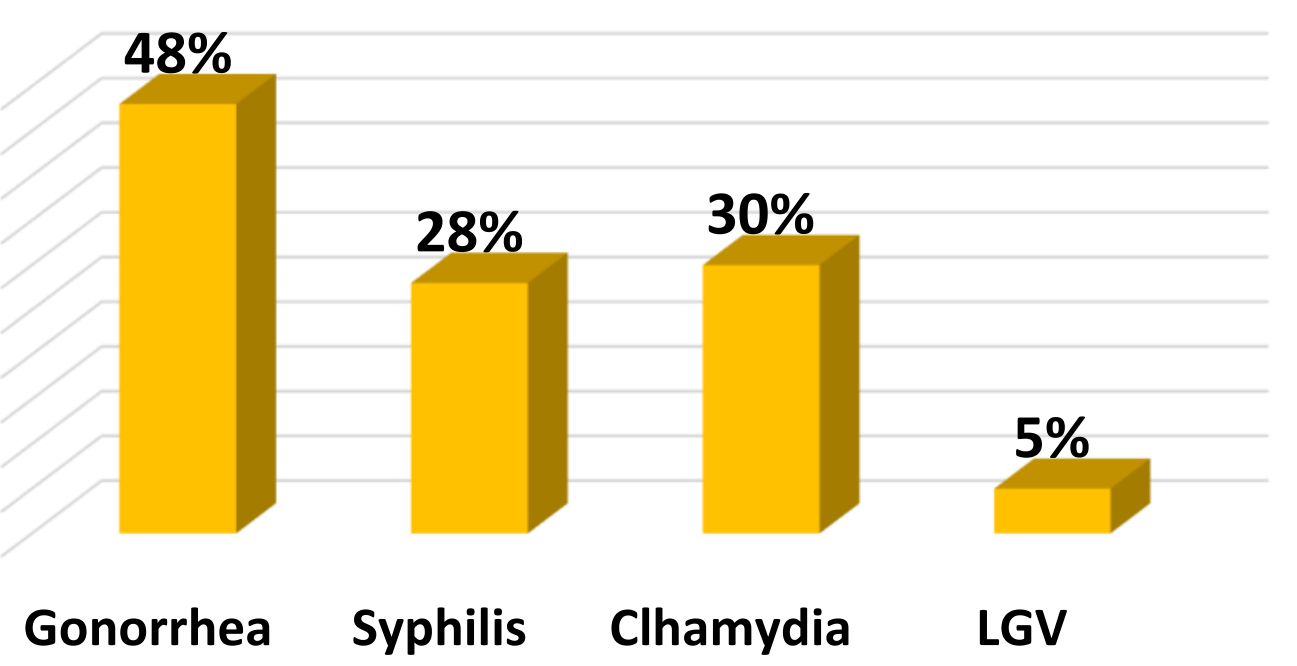

The $87.7 \%(n=142)$ of the rSCV reported drugs use in the last year
Type of drugs and prevalence. 2014-2016
$91 \% \quad$
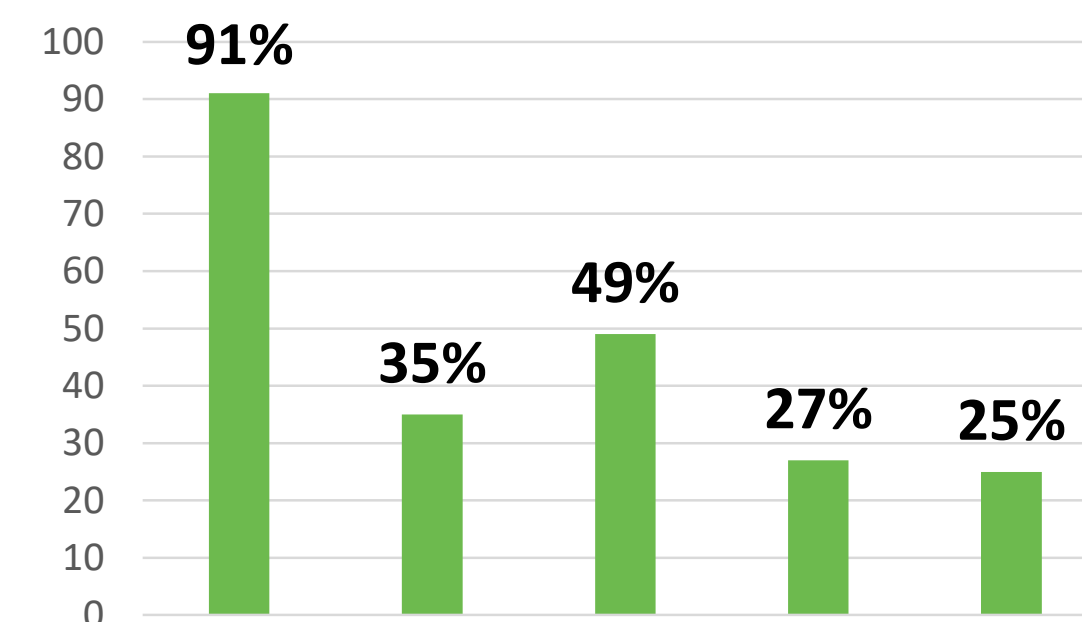

$22 \%$

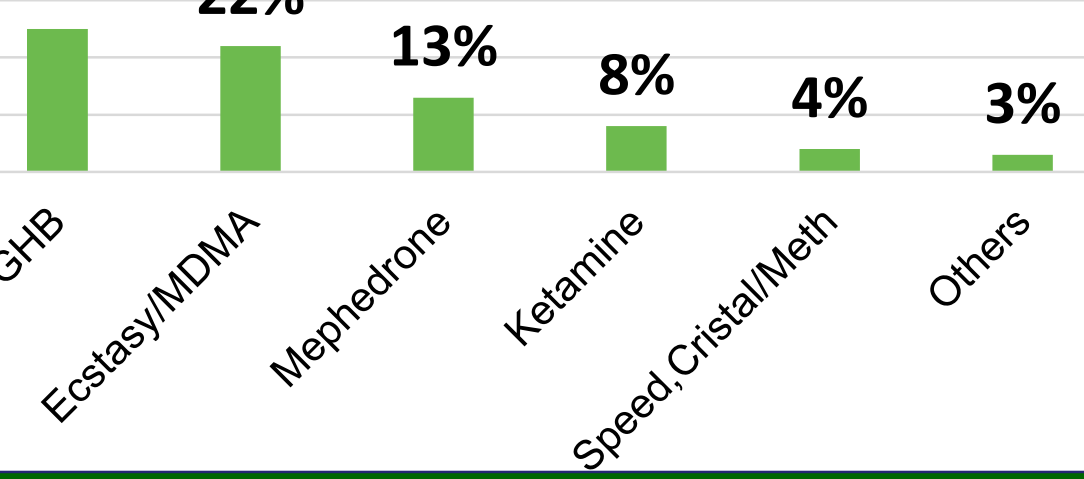

The $73.5 \%$ ( $n=119)$ of the rSCV had UPS under the effect of these substances. Type of drugs and prevalence. 2014-2016

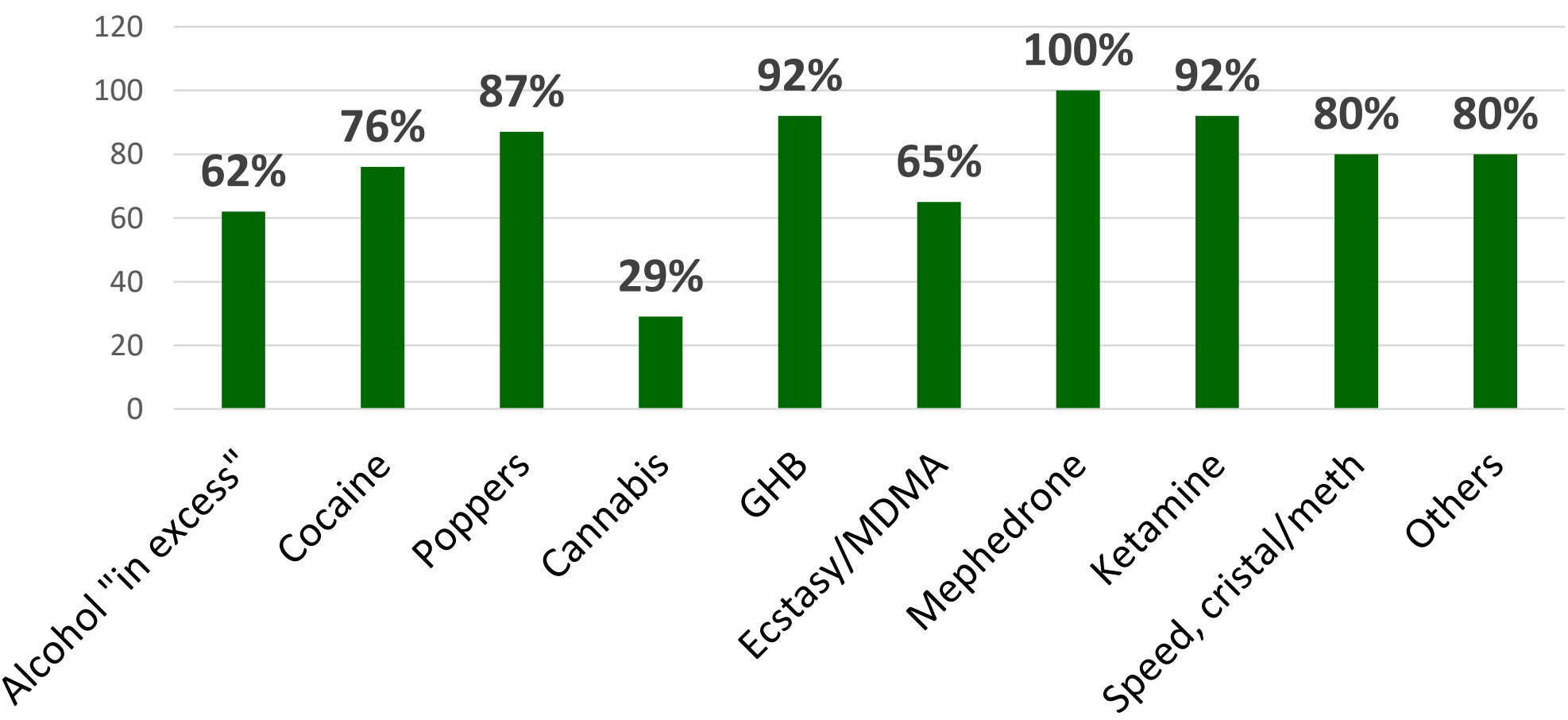

\section{Conclusions}

Recreational drugs consumption was related to unprotected sex with multiple sexual partners and increased the risk to acquire STIs. Although alcohol was the most used substance, the most associated drugs with UPS were: mephedrone, GHB, ketamine and poppers. It is advisable 